\title{
NONINVASIVE TEAR FILM BREAK-UP TIME ASSESSMENT USING HANDHELD LIPID LAYER EXAMINATION INSTRUMENT
}

\author{
Sania Vidas Pauk ${ }^{1}$, Igor Petriček ${ }^{1}$,Tomislav Jukić ${ }^{1}$, Smiljka Popović-Suić ${ }^{1}$, \\ Martina Tomić ${ }^{2}$, Miro Kalauz ${ }^{1}$, Sonja Jandroković ${ }^{1}$ and Sanja Masnec ${ }^{1}$ \\ ${ }^{1}$ Department of Ophthalmology, Zagreb University Hospital Centre, Zagreb, Croatia; \\ ${ }^{2}$ Vuk Vrhovac University Clinic for Diabetes, Endocrinology and Metabolic Diseases, \\ Merkur University Hospital, Zagreb, Croatia
}

\begin{abstract}
SUMMARY - The aim was to determine feasibility and reliability of noninvasive tear break-up time (NIBUT) assessment using handheld lipid layer examination instrument, and to compare it with standard tear break-up time (TBUT) test. Fifty patients were enrolled, 31 with and 19 without dry eye symptoms. Schein questionnaire was used to assess dry eye symptoms. During examination, three NIBUT measurements were performed on each eye using handheld instrument, followed by three TBUT measurements. Receiver operating characteristic curves, sensitivity, specificity and logistic regression analysis were generated. Median NIBUT values were significantly shorter in dry eye symptom group than in control group in all three measurements $(9,8$ and $8 \mathrm{~s}$ vs. 21, 22 and $21 \mathrm{~s} ; \mathrm{p}<0.001)$. TBUT values showed no significant difference between the groups in the first measurement $(\mathrm{p}=0.053)$, but the values were significantly shorter in dry eye symptom group in second and third measurements $(\mathrm{p}=0.020)$. The cutoff value to distinguish patients with symptoms of dry eye from control group was 12 seconds for NIBUT and 8 seconds for TBUT, with NIBUT having significantly higher sensitivity, specificity, area under the receiver operating characteristic curve and positive predictive value. NIBUT, measured by handheld lipid layer examination instrument, was superior to TBUT in detecting dry eye.
\end{abstract}

Key words: Cornea; Tears; Surveys and questionnaires; Dry eye syndrome - diagnosis

\section{Introduction}

Tear film stability is the most important indicator of tear film (dys)function ${ }^{1}$. Reduced tear film stability, as well as increased tear osmolarity are hallmarks of all forms of dry eye, as highlighted by the Tear Film and Ocular Surface Society (TFOS) Dry Eye WorkShop (DEWS) definition of dry eye amended by the TFOS DEWS II ${ }^{2,3}$.

According to the National Eye Institute/Industry Workshop, tear film break-up time (TBUT) is accept-

Correspondence to: Sania Vidas Pauk, MD, Department of Ophthalmology, Zagreb University Hospital Centre, Kišpatićeva 12, HR-10000 Zagreb, Croatia

E-mail: sania_vidas@yahoo.com

Received May 24, 2018, accepted July 10, 2018 ed as the global criterion of dry eye ${ }^{4}$, despite the fact that many studies criticized it as imprecise and unreproducible ${ }^{5}$.

Tear film break-up time is a standard, routine and widely accepted test for tear film stability assessment. It is an invasive method that requires instillation of fluorescein solution in the eye. Instillation of fluorescein disturbs tear film equilibrium, resulting in increased evaporation and tear film destabilization ${ }^{6}$. It is usually performed by using standard fluorescein strips or reduced volume of fluorescein solution in order to improve its reproducibility ${ }^{7,8}$. In normal eyes, TBUT values range from 3 seconds (s) to $132 \mathrm{~s}$, with an average of $27 \mathrm{~s}^{9}$. TBUT less than $10 \mathrm{~s}$ suggests an abnormal tear film, with values of $5 \mathrm{~s}$ to $10 \mathrm{~s}$ considered marginal, and less than $5 \mathrm{~s}$ indicative of dry eye $\mathrm{e}^{10}$. The sen- 
sitivity and specificity of TBUT is $75 \%$ and $60 \%$, respectively ${ }^{11}$.

Given the lack of TBUT reproducibility, numerous noninvasive techniques have been reported. These techniques avoid instillation of fluorescein and there is no contact between the measuring instrument and the eye or eyelids. It is also important that the methodology does not substantially alter ocular environment such as ocular surface temperature from illumination systems ${ }^{12}$, enabling tear film assessment in its unaltered condition. Noninvasive testing is considered more precise, repeatable and therefore preferable to invasive testing in tear film stability assessment. Generally, in normal population, TBUT and noninvasive tear break-up time (NIBUT) are poorly correlated, $4+/-12 \mathrm{~s}$, with NIBUT being longer ${ }^{13,14}$. The range in normal population was $4 \mathrm{~s}$ to $214 \mathrm{~s}$, median 4-19 $\mathrm{s}^{15,16}$. However, in patients with dry eye, NIBUT and TBUT values are almost the same ${ }^{13,17}$. The cutoff values for positive finding can be as low as $2.7 \mathrm{~s}$ for automated algorithms and up to $10 \mathrm{~s}$ for subjective observation techniques ${ }^{18-20}$.

Noninvasive tear break-up time test is usually performed by sophisticated and expensive instruments, Tearscope ${ }^{21}$, keratometers, or complicated computerized systems, topographic analysis systems including videokeratoscopy, ocular surface thermography, or lateral shearing interferometry. These instruments are not readily available to most practitioners and are therefore not accepted for everyday clinical practice, which is probably the reason why not many papers describe their clinical use $\mathrm{e}^{3,11,12,19,21-23}$.

Lipid layer on top of the surface of tear film can be visualized on the corneal surface by interference between light reflected from the lipid layer and from interface between that layer and the aqueous layer, in the shape of colored fringes ${ }^{24}$. This method is called interferometry ${ }^{21,25}$. Interferometry uses cold diffuse white light to evaluate lipid layer surface.

Currently, Tearscope is the only commercially available instrument for measuring tear film lipid layer thickness, as well as NIBUT ${ }^{21}$. The instrument is, however, no longer being manufactured, potentially because of its price and scarcity of published data describing its use.

However, it is still important to assess tear film lipid layer, as it gives us an idea which layer, aqueous or lipid, is deficient. In recent literature, there is descrip- tion of the new handheld lipid layer examination instrument ${ }^{25,26}$. It consists of commercially available handheld LED torch, modified with opaque white filter that enables it to project wide diffuse white light onto the corneal surface. As it produces the same type of light as Tearscope, it can measure lipid layer thickness and NIBUT in the same way as Tearscope, as is explained in more detail in the Methods section, and it therefore might enable NIBUT measurement to become part of everyday clinical practice.

The aim of this study was to determine the feasibility and reliability of NIBUT assessment using handheld lipid layer examination instrument, and to compare the values with those obtained by standard test, TBUT, in order to investigate the possibility of using it in routine practice.

\section{Subjects and Methods}

This cross-sectional study was conducted at the Department of Ophthalmology, Zagreb University Hospital Center, Zagreb, Croatia. A total of $50 \mathrm{pa}-$ tients visiting Ophthalmology Outpatient Department over a two-month period were enrolled in the study. First, a case history using standardized Schein questionnaire, modified for issues relevant to this research, was obtained in order to determine the extent of dry eye symptoms (Table 1$)^{27}$. Afterwards, all subjects underwent standard ophthalmology examination including TBUT and NIBUT measurement, using slit lamp and handheld lipid layer examination instrument. Inclusion criteria required subjects to be 18 or older, not to be contact lens wearers, to have normal other anterior ocular surface findings, and not to use any topical ophthalmic medication. Excluded were all patients with previous ocular trauma, acute infection, glaucoma, ocular surgery in the past year, any other ocular surface diseases and irregularities, systemic diseases or medications that would alter the ocular surface, or poorly cooperating patients. The study protocol was approved by the institutional Ethics Committee and was performed in adherence with the guidelines of the Declaration of Helsinki. The patients received both written and oral information about the study and signed a written informed consent.

Schein questionnaire is a disease-specific questionnaire used to measure patient-reported symptoms of dry eye and to quantify the specific impact of dry eye 
on vision related quality of life. Schein subscale scores can range from 0 to 20 , with higher scores indicating more problems or symptoms ${ }^{27}$.

During slit lamp examination, NIBUT measurement was performed first by using handheld lipid layer examination instrument. The subject was asked to blink once and then to refrain from further blinking. A stopwatch was started after the last complete blink. During that period, NIBUT was measured using slit lamp and handheld lipid layer examination instrument. The instrument was held obliquely and $5 \mathrm{~cm}$ from the corneal surface in order to illuminate as large corneal surface area as possible. At the first sign of irregularities on the lipid layer surface, the stopwatch was stopped and the time noted. If the subject blinked

\section{Table 1. Schein questionnaire}

\begin{tabular}{|l|}
\hline There are 6 questions, as follows: \\
1. Do your eyes ever feel dry? \\
2. Do you ever feel a gritty or sandy sensation \\
in your eye? \\
3. Do your eyes ever have a burning sensation? \\
4. Are your eyes ever red? \\
5. Do you notice much crusting on your lashes? \\
6. Do your eyes ever get stuck shut in the morning? \\
Symptoms are graded as: \\
- rarely \\
- sometimes \\
- often or \\
\hline
\end{tabular}

during measurement, the test was halted and then repeated after several blinks. The time interval between the last blink and the first sign of breaks in uniform lipid layer surface was recorded in seconds as the NIBUT. The procedure was repeated three times on both eyes, first right than left eye (Fig. 1).

After NIBUT measurement, TBUT was measured using standardized fluorescein strips (Biotech, Fluorescein Sodium Ophthalmic Strip USP, Lake Forest, IL, USA). For TBUT measurement, the subject was seated comfortably and asked to look downwards. The upper lid of the right eye was slightly lifted and the fluorescein strip was moistened with saline. The excess fluid was shaken off from the strip, and it was then used to stain the ocular surface. Subject was asked to keep the eyes open while looking straight ahead. The stopwatch was started after the last blink and the appearance of dry spots on the corneal surface was observed with the cobalt blue light of the slit lamp. At the first appearance of dry spots, the stopwatch was stopped. The time interval between the last blink and the first appearance of dry spots was recorded in seconds as the TBUT. The procedure was repeated three times on both eyes, first right than left eye. A single examiner (S.V.P.) collected the data.

Handheld lipid layer examination instrument works on the same physical principle as Tearscope. It is not harmful, hazardous or uncomfortable for the $\mathrm{pa}^{-}$ tient. Its light source are 9 single LED lamps covered with uniformly opaque wide white plastic filter, which

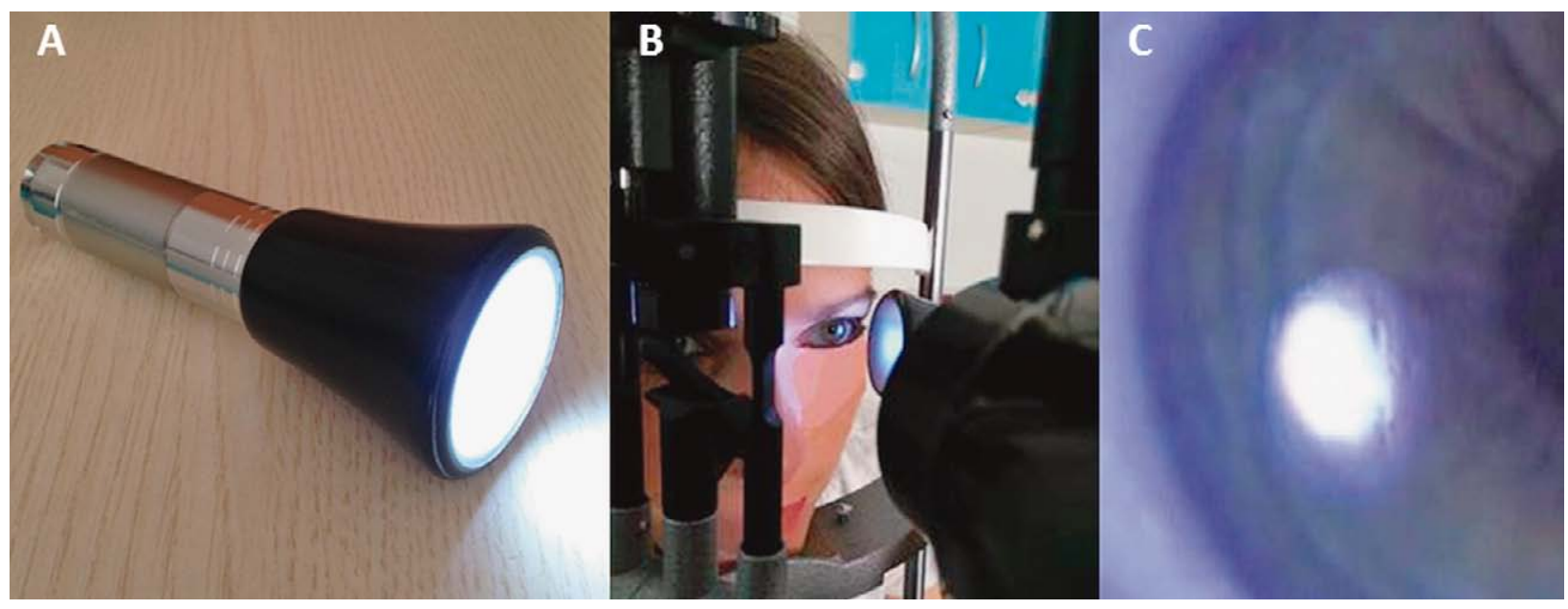

Fig. 1. (A) Handheld lipid layer examination instrument; (B) noninvasive tear fllm break-up time assessment using slit lamp and handheld lipid layer examination instrument (the person, demonstrator in Figure $1 B$ is not a patient but the first author); (C) appearance of irregularities on the lipid layer surface after a blink. 
creates bright, wide and uniform reflection from the corneal surface. The light source satisfies the criteria for class 1 light source (class 1: eye-safe under all operating conditions (LED and Laser Classification System in EN 60825-1 and IEC 60825-1)). It fits in the pocket, and the price is only slightly higher than that of a regular flashlight ${ }^{25,26}$. It is used together with slit lamp (Fig. 1). This instrument is not currently commercially available, but several hundreds were manufactured by several pharmaceutical companies for promotional purposes and distributed for free among $\mathrm{Eu}-$ ropean ophthalmologists. However, due to its simplicity, it can be very easily made again.

Statistical analyses were performed using Statistica software package version 12 (StatSoft, Inc., Tulsa, OK, USA) and SPSS software package version 24.0. (IBM, Armonk, NY, USA). The results were presented as means $\pm \mathrm{SD}$, median (min-max) and percentages. Differences in distributions of continuous data were determined by T-test. Differences in distributions of categorical data were evaluated by $\chi^{2}$-test. The normality of distribution was tested by Shapiro-Wilks W test and homogeneity of variance by Leven test. The Spearman rank correlation test was used. The sensitivity and specificity were calculated and area under the ROC curve (AUC) was used to assess the ability to differentiate dry eyes from normal eyes with each testing parameter. An AUC of 1.0 represents perfect discrimination, whereas an area of 0.5 represents chance discrimination. Logistic regression analysis was used to assess the strength and independence of associations. The level of statistical significance was set at $\mathrm{p}<0.05$.

\section{Results}

This study included 50 patients (10 male and 40 female), mean age $58.52 \pm 14.86$ years. According to dry eye symptoms evaluated by Schein questionnaire, patients were divided into two groups: group with dry eye symptoms (Schein questionnaire score 1-20) and control group without dry eye symptoms (Schein questionnaire score 0 ). Descriptive statistics of basic characteristics of patients included in the study are shown in Table 2.

Dry eye symptom group had a significantly shorter NIBUT than control group in all three measurements, especially in the second measurement $(8(2-30)$ vs. 22 $(10-48), t=-4.96, p<0.001)$. TBUT did not significant-
Table 2. Basic characteristics of subjects divided into two groups according to dry eye symptoms evaluated by Schein questionnaire

\begin{tabular}{|l|l|l|l|l|}
\hline & $\begin{array}{l}\text { Dry eye } \\
\text { group } \\
(\mathrm{n}=31)\end{array}$ & $\begin{array}{l}\text { Control } \\
\text { group } \\
(\mathrm{n}=19)\end{array}$ & $\mathrm{t}^{-\mathrm{a}} \chi^{-\mathrm{b}}$ & $\mathrm{p}$ \\
\hline $\begin{array}{l}\text { Age } \\
\text { (years) }^{*}\end{array}$ & $56.97 \pm 14.11$ & $61.05 \pm 16.08$ & $-0.94^{\mathrm{a}}$ & $0.351^{\mathrm{a}}$ \\
$\begin{array}{l}\text { Gender } \\
(\mathrm{m} / \mathrm{f})^{* *}\end{array}$ & $13 / 87$ & $32 / 68$ & $2.57^{\mathrm{b}}$ & $<\mathbf{0 . 0 0 1}^{\mathrm{b}}$ \\
\hline
\end{tabular}

*mean $\pm \mathrm{SD}$; ${ }^{* *}$ percentage; ${ }^{\mathrm{t}}$-test $\mathrm{df}=48$; ${ }^{\mathrm{b}} \chi^{2}$-test $\mathrm{df}=1$

Table 3. NIBUT and TBUT values in the first, second and third measurement of the right eye in patients divided into two groups according to dry eye symptoms evaluated by Schein questionnaire

\begin{tabular}{|c|c|c|c|c|}
\hline & $\begin{array}{l}\text { Dry eye } \\
\text { group } \\
(n=31)\end{array}$ & $\begin{array}{l}\text { Control } \\
\text { group } \\
(n=19)\end{array}$ & $\mathrm{t}$-value & $\mathrm{p}$ \\
\hline $\begin{array}{l}\text { NIBUT } \\
1^{\text {st }} \text { testing (s) }\end{array}$ & $9(3-35)$ & $21(4-43)$ & -4.17 & $<0.001$ \\
\hline $\begin{array}{l}\text { NIBUT } \\
2^{\text {nd }} \text { testing }(\mathrm{s})\end{array}$ & $8(2-30)$ & $22(10-48)$ & -4.96 & $<0.001$ \\
\hline $\begin{array}{l}\text { NIBUT } \\
3^{\text {rd }} \text { testing (s) }\end{array}$ & $9(2-32)$ & $21(3-50)$ & -4.37 & $<0.001$ \\
\hline $\begin{array}{l}\text { TBUT } \\
1^{\text {st }} \text { testing (s) }\end{array}$ & $5(2-28)$ & $10(3-20)$ & -1.97 & 0.053 \\
\hline $\begin{array}{l}\text { TBUT } \\
2^{\text {nd }} \text { testing (s) }\end{array}$ & $5(2-24)$ & $8(3-22)$ & -2.40 & 0.020 \\
\hline $\begin{array}{l}\text { TBUT } \\
3^{\text {rd }} \text { testing }(\mathrm{s})\end{array}$ & $5(2-27)$ & $10(3-28)$ & -2.40 & 0.020 \\
\hline
\end{tabular}

median $(\min -\max ) \mathrm{T}$-test $\mathrm{df}=48$; NIBUT $=$ noninvasive break-up time; $\mathrm{TBUT}=$ tear break-up time; $\mathrm{s}=$ second

ly differ in the first measurement between the observed groups $(p=0.053)$, although in the second and third measurements it was significantly shorter in dry eye symptom group than in control group $(p<0.020)$. When comparing differences of NIBUT and TBUT in the first, second and third measurements between the groups, it can be noticed that the differences were much more significant in NIBUT scores than in TBUT scores $(<0.001,<0.001,<0.001$ vs. $0.053,0.020$, 0.020) (Table 3).

A significant positive correlation between NIBUT and TBUT was recorded in all three measurements 
( $\mathrm{p}<0.001)$, with the most significant correlation observed in the third measurement (Spearman $\mathrm{R}=0.832$, $\mathrm{t}(\mathrm{N}-2)=10.399, \mathrm{p}<0.001$ ) (Table 4, Fig. 2).

The most sensitive and specific NIBUT threshold between normal and patients with dry eye symptoms in our study was found to be 12 seconds. At the cutoff of $12 \mathrm{~s}$, NIBUT showed $65.62 \%$ sensitivity and $73.68 \%$ specificity in the first testing, $74.19 \%$ and $89.47 \%$ in the second, and $70.97 \%$ and $83.33 \%$ in the third measurement (Table 5). By contrast, at cutoff of $10 \mathrm{~s}$, NIBUT showed poor sensitivity $(58.32 \%, 64.52 \%$ and $61.37 \%)$ and poor specificity $(54.12 \%, 69.72 \%$ and $61.19 \%)$ in all three measurements. TBUT threshold between normal and patients with dry eye symptoms in our study was found to be most sensitive and specific at 8 seconds. At cutoff of $8 \mathrm{~s}$, TBUT showed $74.19 \%$ sensitivity and $68.42 \%$ specificity in the first, $77.42 \%$ and $78.95 \%$ in the second, and $77.42 \%$ and $84.21 \%$ in the third measurement (Table 5). By contrast, at a cutoff of $10 \mathrm{~s}$, TBUT showed poor sensitivity $(59.72 \%, 63.12 \%$ and $71.97 \%)$ and poor specificity $(47.72 \%, 52.61 \%$ and $60.39 \%)$ in all three measurements. The results also indicated that the critical value

\section{Table 4. Correlation between NIBUT and TBUT} in the first, second and third measurement of the right eye in study patients

\begin{tabular}{|l|l|l|l|}
\hline \multirow{2}{*}{} & \multicolumn{3}{|l|}{ Correlation between NIBUT and TBUT } \\
\cline { 2 - 4 } & Spearman R & $\mathrm{t}(\mathrm{N}-2)$ & $\mathrm{p}$ \\
\hline $1^{\text {st }}$ testing & 0.749 & 7.834 & $<\mathbf{0 . 0 0 1}$ \\
$2^{\text {nd }}$ testing & 0.772 & 8.423 & $\mathbf{< 0 . 0 0 1}$ \\
$3^{\text {rd }}$ testing & 0.832 & 10.399 & $\mathbf{< 0 . 0 0 1}$ \\
\hline
\end{tabular}

NIBUT $=$ noninvasive break-up time; TBUT = tear break-up time of 12 seconds for NIBUT achieved the best sensitivity and specificity in the second measurement $(74.19 \%$ and $89.47 \%$, respectively), while the TBUT critical value of 8 seconds achieved the best sensitivity and specificity in the third measurement $(77.42 \%$ and $84.21 \%$, respectively). NIBUT in the first, second and third measurements showed higher area under the ROC curve (AUC) than TBUT in all three measurements, which emphasized better capability of NIBUT than TBUT in detecting dry eye symptoms. The highest AUC NIBUT had in the second measurement (0.855), which was significantly higher than the best TBUT AUC in the third measurement (0.722) (Table 5, Fig. 3).

The highest positive predictive value (PPV) and negative predictive value (NPV) of NIBUT were observed in the second measurement (PPV $=92.00 \%$, NPV $=68.00 \%$ ), and of TBUT in the third measurement (PPV=88.88\%, NPV=69.57\%) (Table 6).

Logistic regression analysis showed that female gender, Schein questionnaire score, NIBUT in the second and third measurements, and TBUT in the third measurement were the main predictors and indicators of dry eye symptoms. The increasing prevalence of dry eye symptoms was significantly related to female gender $(\mathrm{OR}=0.31,95 \% \mathrm{CI}$ 0.26-0.37, $\mathrm{p}<0.001)$ and higher Schein questionnaire score $(\mathrm{OR}=0.19$, 95\%CI 0.06-0.58, $\mathrm{p}=0.003$ ). Lower NIBUT observed in the second and third measurements and TBUT in the third measurement also increased the prevalence of dry eye symptoms to a significant extent $(\mathrm{OR}=0.30$, 95\%CI 0.21-0.47, $\mathrm{p}<0.001 ; \mathrm{OR}=0.72,95 \% \mathrm{CI}$ 0.51$1.00, \mathrm{p}=0.047 ; \mathrm{OR}=0.09,95 \% \mathrm{CI} 0.01-0.84, \mathrm{p}=0.029$ ) (Table 7).
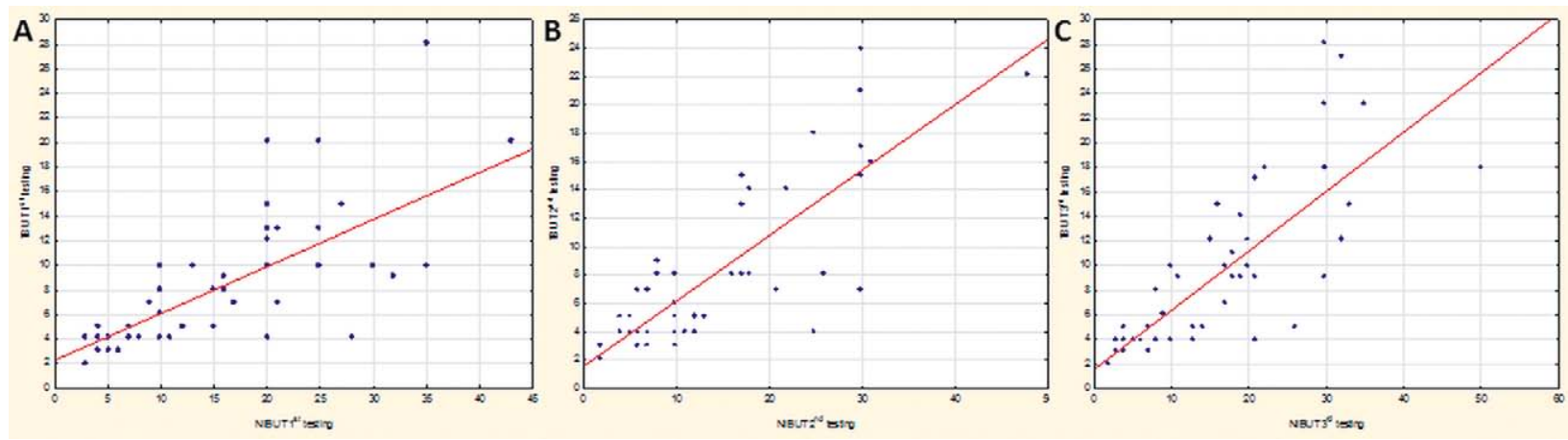

Fig. 2. Correlation between noninvasive break-up time (NIBUT) and tear break-up time (TBUT) on the (A) $1^{\text {st }}$, (B) $2^{\text {nd }}$ and $(C) 3^{\text {rd }}$ measurement of the right eye in study patients. 
Table 5. Comparison of sensitivity, specificity and area under the ROC curve between NIBUT and TBUT in the first, second and third measurement of the right eye in study patients

\begin{tabular}{|l|l|l|l|l|l|l|l|}
\hline & Sensitivity (\%) & Specificity (\%) & AUC & AUC & Sensitivity (\%) & Specificity (\%) & \\
\hline NIBUT 1 $^{\text {st }}$ & 65.62 & 73.68 & 0.809 & 0.702 & 74.19 & 68.42 & TBUT $1^{\text {st }} \mathrm{t}$ \\
NIBUT 2 $^{\text {nd }}$ & 74.19 & 89.47 & 0.855 & 0.701 & 77.42 & 78.95 & TBUT 2 $^{\text {nd }} \mathrm{t}$ \\
NIBUT 3 $^{\text {rd }}$ & 70.97 & 83.33 & 0.818 & 0.722 & 77.42 & 84.21 & TBUT 3 $3^{\text {rd }} \mathrm{t}$ \\
\hline
\end{tabular}

$\mathrm{AUC}=$ area under the ROC curve; NIBUT = noninvasive break-up time; TBUT = tear break-up time
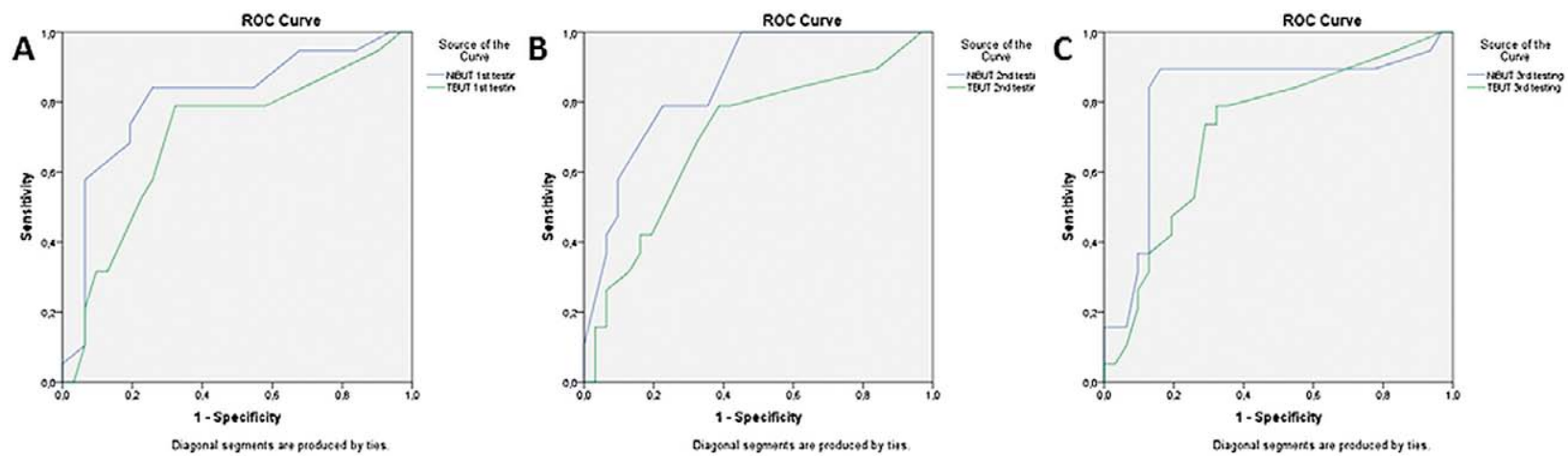

Fig. 3. ROC curves for noninvasive break-up time (NIBUT) and tear break-up time (TBUT) in the (A) $1^{\text {st }}$, (B) $2^{\text {nd }}$ and $(C) 3^{\text {rd }}$ measurement of the right eye in study subjects.

Table 6. Positive and negative predictive values of NIBUT and TBUT in the first, second and third measurement of the right eye in study patients

\begin{tabular}{|l|l|l|l|l|l|}
\hline & PPV (\%) & NPV (\%) & PPV (\%) & NPV (\%) & \\
\hline NIBUT 1 $^{\text {st }}$ testing & 81.48 & 57.69 & 79.31 & 61.90 & TBUT $1^{\text {st }}$ testing \\
NIBUT 2 $^{\text {nd }}$ testing & 92.00 & 68.00 & 85.71 & 68.18 & TBUT 2 \\
NIBUT $^{\text {rd }}$ testing & 87.50 & 60.87 & 88.88 & 69.57 & TBUT 3 $3^{\text {rd }}$ testing \\
\hline
\end{tabular}

$\mathrm{PPV}=$ positive predictive value $\mathrm{NPV}=$ negative predictive value; $\mathrm{NIBUT}=$ noninvasive break-up time; $\mathrm{TBUT}=$ tear break-up time

Table 7. Predictors and indicators of dry eye by use of logistic regression analysis

\begin{tabular}{|c|c|c|}
\hline & Dry eye & \\
\hline Variable & OR $(95 \% \mathrm{CI})$ & $\mathrm{p}$ \\
\hline Age & $1.02(0.95-1.09)$ & 0.623 \\
\hline Gender (female) & $0.31(0.26-0.37)$ & $<0.001$ \\
\hline Schein questionnaire & $0.19(0.06-0.58)$ & 0.003 \\
\hline NIBUT $1^{\text {st }}$ testing & $1.18(0.91-1.52)$ & 0.194 \\
\hline NIBUT $2^{\text {nd }}$ testing & $0.30(0.21-0.47)$ & $<0.001$ \\
\hline NIBUT $3^{\text {rd }}$ testing & $0.72(0.51-1.00)$ & 0.047 \\
\hline TBUT $1^{\text {st }}$ testing & $1.20(0.92-1.57)$ & 0.177 \\
\hline TBUT $2^{\text {nd }}$ testing & $1.02(0.55-1.87)$ & 0.829 \\
\hline TBUT $3^{\text {rd }}$ testing & $0.09(0.01-0.84)$ & 0.029 \\
\hline
\end{tabular}

NIBUT = noninvasive break-up time; TBUT = tear break-up time

\section{Discussion}

Lack of reports, inaccessibility and lack of uniformity of NIBUT assessment methods make their interpretation difficult, especially in everyday clinical use. NIBUT values obtained using different noninvasive techniques widely differ. Patel et al. ${ }^{28}$ found the mean tear thinning time (TTT) values to be $\sim 16 \mathrm{~s}$ for normal and $7 \mathrm{~s}$ for dry eyes using Bausch and Lomb keratometer, whereas Craig et al. ${ }^{23}$ found it to be $18.6 \mathrm{~s}$ using modified Bausch and Lomb keratometer. Mengher et al. ${ }^{20}$ report NIBUT values using a hemispheric bowl with rectangular grid pattern, ranging from $4 \mathrm{~s}$ to $214 \mathrm{~s}$, with a mean of $42 \mathrm{~s}$. In the study by Fuller et al..$^{29}$, the mean NIBUT obtained by Keratograph 4 in 
Caucasians was found to be $8.9 \mathrm{~s}$ with minimum of 0.2 $\mathrm{s}$ and maximum of $24 \mathrm{~s}$, and mean NIBUT $9 \pm 4 \mathrm{~s}$. Koh et $a .^{30}$ report on the mean NIBUT of $9.7 \pm 6.7 \mathrm{~s}$ in control group and $4.6 \pm 1.3 \mathrm{~s}$ in dry eye group, obtained by Keratograph M5, whereas Hong et al. ${ }^{31}$ report it to be $4.3 \pm 0.3 \mathrm{~s}$ in normal group and $2.0 \pm 0.2 \mathrm{~s}$ in dry eye group as measured by Oculus Keratograph. According to Gumus et $a ._{.}^{32}$, the mean NIBUT values were $4.91 \pm 1.62 \mathrm{~s}$ in normal subjects and $2.40 \pm 2.47 \mathrm{~s}$ in patients with dry eye symptoms using Tear Stability Analysis System. Sue et al. published a new method, ocular surface thermography, used to measure NIBUT. The mean NIBUT measured by that method was $4.5 \pm 0.9 \mathrm{~s}$ and $2.1 \pm 1.1 \mathrm{~s}$ in normal and dry eye subjects, respectively ${ }^{33}$. Data on this method are limited to a single study. Finally, Nosch et al. ${ }^{34}$ report median NIBUT in 43 normal patients obtained by Tearscope to be $34.55 \mathrm{~s}$, whereas Sharanjeet-Kaur et al. found NIBUT values using Tearscope to be significantly shorter; the mean NIBUT in normal Malays and Chinese was $7.74 \pm 3.34 \mathrm{~s}^{35}$. In a study published by Elliot et al. ${ }^{36}$, the mean NIBUT values using both Tearscope and Oculus Keratograph in normal subjects were $15.9 \pm 10.7 \mathrm{~s}$ and $10.9 \pm 3.9 \mathrm{~s}$, respectively. Generally, NIBUT values measured by subjective methods were significantly higher than those obtained by objective automated algorithms. Also, NIBUT values in dry eye group were twice lower than those in normal subjects.

In our study, median NIBUT values using handheld lipid layer examination instrument were between 8 and $9 \mathrm{~s}$ in patients with dry eye symptoms and between 21 and $22 \mathrm{~s}$ in control group. Median TBUT values were $\sim 5 \mathrm{~s}$ in patients with dry eye symptoms and $8-10 \mathrm{~s}$ in control group. NIBUT values were longer in both groups, and the difference between two tests was more pronounced in control group, where normal tear film function was assumed, with NIBUT being significantly longer. However, in dry eye symptom group where most patients had poor tear film stability, the values between the tests almost equalized.

Tear film break-up time values in second and third measurements and NIBUT values in all three measurements were significantly shorter in patients with dry eye symptoms than in control group, while NIBUT indicated more significant difference between the two groups, showing better diagnostic ability to discriminate patients with dry eye symptoms from normal pa- tients. First TBUT measurement produced results without significant difference between the groups, questioning the accuracy of that measurement. The reasons may be change in tear film physiology due to fluorescein instillation and insufficient time for fluorescein to spread uniformly in the tear film. Results were improved in second and third measurements, showing that multiple TBUT testing improved its reproducibility. In contrast to TBUT, NIBUT detected patients with symptoms of dry eye right away with first measurement.

Noninvasive tear break-up time and TBUT values showed positive correlation in all three measurements, showing that both diagnostic tests measure the same physical phenomenon, namely, the moment of tear film destabilization over the corneal surface after blink. Median NIBUT values in patients with symptoms of dry eye were 3-4 seconds longer than TBUT values. In normal subjects, there was larger dispersion of results of both tests and values were poorly correlated. Also, reproducibility of both tests was better in dry eye symptom group. Therefore, both tests showed better performance in the group of patients with dry eye symptoms.

The cutoff value with greatest sensitivity, specificity, PPV and NPV, distinguishing patients with dry eye symptoms and normal subjects, was 12 seconds for NIBUT and 8 seconds for TBUT. However, NIBUT showed higher specificity and sensitivity, as well as higher AUC and PPV than TBUT in all three measurements. NIBUT measurements where strongly connected with dry eye symptoms.

Although simple, the handheld instrument used in this study showed that NIBUT values obtained by using it were reproducible and consistent, and as such show that this tool and the way it was used is clinically acceptable and useful.

Considering the results of our study, this method could replace Tearscope and finally allow simple, accessible and practical NIBUT assessment. However, further investigations with more patients are recommended to strengthen the value of our results.

\section{Conclusion}

In this study, we analyzed the feasibility of NIBUT measured using handheld lipid layer examination instrument compared to standard TBUT test. The cutoff 
value with greatest sensitivity, specificity, PPV and NPV, distinguishing patients with dry eye symptoms and normal subjects, was 12 seconds for NIBUT and 8 seconds for TBUT. NIBUT measured in this way showed better diagnostic ability to discriminate patients with dry eye symptoms from normal group of patients even with first measurement, and was strongly connected with dry eye symptoms. According to our results, NIBUT measured with handheld lipid layer examination instrument is a simple, accessible, practical, portable and noninvasive method that showed better diagnostic performance than standard TBUT in detecting patients with dry eye symptoms.

\section{References}

1. Rieger G. The importance of the precorneal tear film for the quality of optical imaging. Br J Ophthalmol. 1992;76:157-8.

2. International Dry Eye Workshop. The definition and classification of dry eye disease: report of Definition and Classification Subcommittee of International Dry Eye Workshop. Ocul Surf. 2007;5:75-92.

3. Craig JP, Nichols KK, Akpek EK, Caffery B, Dua HS, Joo CK, et al. TFOS DEWS II Definition and Classification Report. Ocul Surf. 2017;15(3):276-83. doi: 10.1016/j.jtos.2017.05.008

4. Lemp MA. Report of the National Eye Institute/Industry Workshop on Clinical Trials in Dry Eye. CLAO J. 1995;23: 221-32.

5. Lee JH, Kee CW. The significance of tear film break-up time in the diagnosis of dry eye syndrome. Korean J Ophthalmol. 1988;2:69-71.

6. Trees GR, Tomlinson A. Effect of artificial tear solutions and saline on tear film evaporation. Optom Vis Sci. 1990;67: 886-90.

7. Korb DR, Greiner JV, Herman J. Comparison of fluorescein break-up time measurement reproducibility using standard fluorescein strips versus the Dry Eye Test (DET) method. Cornea. 2001;20:811-5.

8. Biuk D, Vinković M, Matić S, Bradvica M, Biuk E, Benašić T. Sensitivity of diagnostic tests for dry eye in patients with blepharospasm. Acta Clin Croat. 2017;56(3):375-81. doi: 10.20471/acc.2017.56.03.03.

9. Norn MS. Dead, degenerate and living cells in conjunctival fluid and mucous thread. Acta Ophthalmol. 1969;47:1102-15.

10. Pflugfelder SC, Tseng SC, Sanabria O, Kell H, Garcia CG, Felix C, et al. Evaluation of subjective assessments and objective diagnostic tests for diagnosing tear-film disorders known to cause ocular irritation. Cornea. 1998;17:38-56.

11. Goto T, Zheng X, Okamoto S, Ohashi Y. Tear film stability analysis system. Introducing a new application for videokeratoscopy. Cornea. 2004;23:65-70.
12. Szczesna DH, Iskander DR. Lateral shearing interferometry for analysis of tear film surface kinetics. Optom Vis Sci. 2010; 87:513-7. doi: 10.1097/OPX.0b013e3181e17279.

13. Nichols JJ, Nichols KK, Puent B, Saracino M, Mitchell GL. Evaluation of tear film interference patterns and measures of tear break-up time. Optom Vis Sci. 2002;79:363-9.

14. Tonge SR, Hunsaker J, Holly FJ. Non-invasive assessment of tear film break-up time in a group of normal subjects - implications for contact lens wear. J Br Cont Lens Assoc. 1991;14: 201-5.

15. Madden RK, Paugh JR, Wang C. Comparative study of two non-invasive tear film stability techniques. Curr Eye Res. 1994; 13:263-9.

16. Willcox MDP, Argüeso P, Georgiev GA, Holopainen JM, Laurie GW, Millar TJ, et al. TFOS DEWS II Tear Film Report. Ocul Surf. 2017;15(3):366-403. doi: 10.1016/j.jtos.2017.03.006.

17. Lan W1, Lin L, Yang X, Yu M. Automatic noninvasive Tear Breakup Time (TBUT) and conventional fluorescent TBUT. Optom Vis Sci 2014;9:1412-8. doi: 10.1097/OPX.0000000000000418.

18. Jones L1, Downie LE, Korb D, Benitez-Del-Castillo JM, Dana R, Deng SX, et al. TFOS DEWS II Management and Therapy Report. Ocul Surf. 2017;15(3):575-628. doi: 10.1016/j.jtos.2017.05.006.

19. Hong J, Sun X, Wei A, Cui X, Li Y, Qian T, et al. Assessment of tear film stability in dry eye with a newly developed keratograph. Cornea. 2013;32:716-21. doi: 10.1097/ICO.0b013e3182714425.

20. Mengher LS, Bron AJ, Tonge SR, Gilbert DJ. A non-invasive instrument for clinical assessment of the pre-corneal tear film stability. Curr Eye Res. 1985;4:1-7.

21. Keeler Ltd. Tearscope. Tearscope Plus Clinical Handbook and Tearscope Plus Instructions. Windsor: Keeler Ltd, Broomall: Keeler Insts Inc., 1997.

22. Best N, Drury L, Wolffsohn JS. Clinical evaluation of the Oculus Keratograph. Cont Lens Anterior Eye. 2012;35:171-4. doi: 10.1016/j.clae.2012.04.002.

23. Sweeney DF, Millar TJ, Raju SR. Tear film stability: a review. Exp Eye Res 2013;117:28-38. doi: 10.1016/j.exer.2013.08.010.

24. Norn MS. Semiquantitative interference study of the fatty layer of precorneal tear film. Acta Ophthalmol. 1979;57:766-74.

25. Petriček I. Handheld tear film lipid layer thickness and non invasive tear break up time assessment tool.J Clin Ophthalmol Eye Disord. 2017;1(2):1009.

26. Petriček I. Važnost lipidnog sloja suznog filma i načini njegove dijagnostike. Medix. 2011:94;130-4. (in Croatian)

27. Schein OD, Tielsch JM, Munõz B, Bandeen-Roche K, West S. Relation between signs and symptoms of dry eye in the elderly. A population-based perspective. Ophthalmology. 1997;104: 1395-401.

28. Patel S, Murray D, McKenzie A, Shearer DS, McGrath BD. Effects of fluorescein on tear breakup time and on tear thinning time. Am J Optom Physiol. 1985;62:188-90. 
29. Fuller DG, Potts K, Kim J. Noninvasive tear breakup times and ocular surface disease. Optom Vis Sci. 2013;90:1086-91. doi: 10.1097/OPX.0000000000000023.

30. Koh S, Ikeda C, Fujimoto H, Oie Y, Soma T, Maeda N, et al. Regional differences in tear film stability and meibomian glands in patients with aqueous-deficient dry eye. Eye Contact Lens. 2016;42:250-5. doi: 10.1097/ICL.0000000000000191.

31. Hong J, Sun X, Wei A, Cui X, Li Y, Qian T, et al. Assessment of tear film stability in dry eye with a newly developed keratograph. Cornea. 2013;32:716-21. doi: 10.1097/ICO.0b013e3182714425.

32. Gumus K, Crockett CH, Rao K, Yeu E, Weikert MP, Shirayama $\mathrm{M}$, et al. Noninvasive assessment of tear stability with the tear stability analysis system in tear dysfunction patients. Invest Ophthalmol Vis Sci. 2011;52:456-61. doi: $10.1167 /$ iovs.10-5292.
33. Su TY, Ho WT, Chang SW, Chiang HK. Thermographic evaluation of tear film break-up time to study tear film stability. Int J Therm Sci. 2016;99:36-40. doi: 10.1136/bjophthalmol-2014-305183.

34. Nosch DS, Pult H, Albon J, Purslow C, Murphy PJ. Relationship between corneal sensation, blinking, and tear film quality. Optom Vis Sci. 2016;93:471-81.

doi: 10.1097/OPX.0000000000000827.

35. Sharanjeet-Kaur, Ho CY, Mutalib HA, Ghazali AR. The relationship between tear ferning patterns and non-invasive tear break-up time in normal Asian population. J Optom. 2016;9: 175-81. doi: 10.1016/j.optom.2015.10.004.

36. Elliott M, Fandrich H, Simpson T, Fonn D. Analysis of the repeatability of tear break-up time measurement techniques on asymptomatic subjects before, during and after contact lens wear. Cont Lens Anterior Eye. 1998;21:98-103.

Sažetak

\section{NEINVAZIVNO MJERENJE PUCANJA SUZNOG FILMA RUČNIM INSTRUMENTOM ZA PROCJENU DEBLJINE LIPIDNOG SLOJA SUZA}

\section{S. Vidas Pauk, I. Petriček, T. Jukic, S. Popović-Suic, M. Tomic, M. Kalauz, S. Jandroković i S. Masnec}

Cilj ovoga istraživanja bio je ispitati pouzdanost mjerenja neinvazivnog testa pucanja suznog filma (NIBUT) pomoću ručnog instrumenta za procjenu debljine lipidnog sloja suza te ovu metodu usporediti sa standardnim invazivnim testom (TBUT). U istraživanje je bilo uključeno 50 ispitanika, 31 sa simptomima suhog oka i 19 bez njih. Za procjenu simptoma suhog oka rabio se standardni Scheinov upitnik. Za vrijeme pregleda provedena su tri mjerenja NIBUT-a pomoću ručnog instrumenta, potom tri mjerenja TBUT-a. Statističkom obradom podataka generirane su ROC krivulje, osjetljivost, specifičnost i regresijska analiza. Prosječna vrijednost NIBUT-a bila je značajno kraća u skupini bolesnika sa simptomima suhog oka nego u kontrolnoj skupini u sva tri mjerenja $(9,8,8$ s prema $21,22,21 \mathrm{~s} ; \mathrm{p}<0.001)$. U prvom mjerenju se vrijednosti TBUT-a nisu značajno razlikovale među skupinama $(\mathrm{p}=0.053)$, no bile su značajno kraće u skupini sa simptomima suhog oka $\mathrm{u}$ drugom i trećem mjerenju ( $\mathrm{p}=0.020)$. Granične vrijednosti testova NIBUT i TBUT bile su 12 i 8 sekunda, no NIBUT je imao bolju osjetljivost, specifičnost, područje ispod krivulje (AUC) te pozitivnu prediktivnu vrijednost. Metoda procjene NIBUT-a pomoću ručnog instrumenta za pregled debljine lipidnog sloja suza pokazala se boljom od testa TBUT u otkrivanju suhog oka.

Ključne riječi: Rožnica; Suze; Ankete i upitnici; Subi keratokonjunktivitis - dijagnostika 